\section{Ultrasonography-guided intra-articular steroid injection in the hip for \\ symptomatic round ligament partial tear or degeneration}

\author{
Yu Sung Yoon ${ }^{1}$, Young Cheol Yoon ${ }^{2}$ \\ 'Department of Radiology, Soonchunhyang University Bucheon Hospital, Soonchunhyang \\ University College of Medicine, Bucheon; '2Department of Radiology, Samsung Medical \\ Center, Sungkyunkwan University School of Medicine, Seoul, Korea
}

Purpose: The objectives of this study were to demonstrate the benefits of ultrasonography-guided intra-articular steroid injection in the hip (UISIH) for the treatment of partial tear or degeneration of the round ligament of the femur and to determine the prognostic factors for this treatment. Methods: We retrospectively analyzed the records of 40 patients who were diagnosed with a partial tear or degeneration of the round ligament of the femur and who underwent UISIH between August 2014 and November 2018. The inclusion criteria were a lack of history of UISIH or other interventional procedure and the presence of follow-up records after the hip injection. The short-term clinical outcome was evaluated at the first follow-up appointment after UISIH. Possible prognostic factors for UISIH such as age, sex, injection side, and average follow-up time were analyzed using the chi-square test, the Fisher exact test, and the t test.

Results: UISIH was found to have been effective in 35 of the 40 patients (87.5\%) at the first follow-up visit. The average follow-up time was 43 days. No significant differences were observed in the clinical outcome of UISIH with respect to age, sex, injection side, or follow-up time.

Conclusion: In this study, we demonstrated that UISIH was a safe and effective treatment in patients with a partial tear or degeneration of the round ligament of the femur over the course of short-term follow-up. Age, sex, injection side, and follow-up time were not identified as prognostic factors for this treatment.

Keywords: Hip pain; Ligamentum teres femoris; Steroid; Injection; Ultrasonography

\section{Introduction}

The round ligament of the femur, also known as the ligamentum teres femoris, is a pyramidal or quadrangular intra-articular ligament of the hip. It originates from the acetabular notch and the transverse acetabular ligament and inserts into the fovea capitis of the femur [1-4]. In recent decades, the development of hip arthroscopy has led to increased interest in the role of the round ligament in hip pain and stability. Tearing of this ligament is a major source of hip pain [5-8],

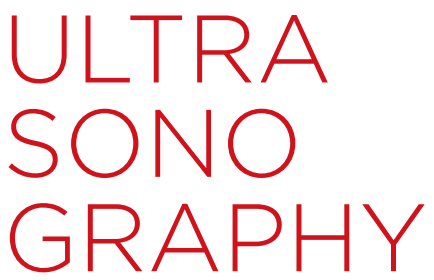

ORIGINAL ARTICLE

https://doi.org/10.14366/usg. 19064 pISSN: 2288-5919 • elSSN: 2288-5943 Ultrasonography 2020;39:281-287

Received: October 31, 2019

Revised: February 28, 2020

Accepted: March 1, 2020

Correspondence to:

Young Cheol Yoon, MD, PhD Department of Radiology, Samsung Medical Center, Sungkyunkwan University School of Medicine, 81 Irwon-ro, Gangnam-gu, Seoul 06351, Korea

Tel. +82-2-3410-2518

Fax.+82-2-3410-2559

E-mail: youngcheol.yoon@gmail.com

This is an Open Access article distributed under the terms of the Creative Commons Attribution NonCommercial License (http://creativecommons.org/ licenses/by-nc/4.0/) which permits unrestricted noncommercial use, distribution, and reproduction in any medium, provided the original work is properly cited.

Copyright (C) 2020 Korean Society of Ultrasound in Medicine (KSUM)

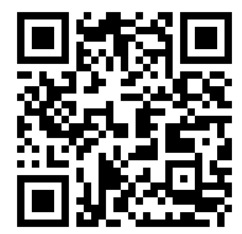

How to cite this article:

Yoon YS, Yoon YC. Ultrasonography-guided intra-articular steroid injection in the hip for symptomatic round ligament partial tear or degeneration. Ultrasonography. 2020 Jul;39(3):281-287. 
constituting the third most common cause of hip pain in athletes who have undergone diagnostic arthroscopy $[7,9]$. Free nerve endings in the round ligament have been suggested to mediate components of the pain response in degenerative arthritis. It is also well established that lesions of the round ligament can cause hip pain in the absence of any other hip pathology. The treatment methods for such lesions are still evolving. Currently, surgical intervention is effective in the majority of patients with round ligament lesions, and the most common procedure is arthroscopic debridement using radiofrequency ablation $[7,10]$.

Ultrasonography-guided intra-articular steroid injection in the hip (UISIH) is a conservative option for the management of hip pain. The effect of UISIH in patients whose sole cause of hip pain is round ligament injury, however, has not been reported. Only a few articles have investigated the effect of steroid injections in the hip for the treatment of osteoarthritis [11]. To the best of our knowledge, the present study is the first to demonstrate the effectiveness of UISIH in patients with a partial tear or degeneration of the round ligament.

\section{Materials and Methods}

All subjects with hip pain underwent a standard evaluation that included a clinical examination as described by Martin and Palmer [12]. If a further examination was needed, imaging studies such as X-ray imaging, computed tomography, or magnetic resonance imaging (MRI) were recommended. Patients whose conditions warranted conservative treatment received medication and physiotherapy. However, when the symptoms failed to improve or the physician deemed it necessary, UISIH was performed [13]. We obtained approval for the retrospective review of patients' records from the local institutional review board, and the requirement for patients to provide informed consent was waived.

\section{Patient Population}

We identified a total of 188 patients who underwent UISIH between August 2014 and November 2018. First, we excluded 105 patients who showed no evidence of partial round ligament tear or degeneration on pre-procedural MRI, including two cases of complete round ligament tear. Next, we excluded 19 patients who displayed additional MRI findings that could be responsible for hip pain, namely femoroacetabular impingement, calcific tendinitis, trochanteric bursitis, ischiofemoral impingement, or femoral head stress fracture. Then, seven patients who had been treated with repeated UISIH and one patient who had undergone total hip replacement arthroplasty were excluded. Thirteen patients who had no post-procedural records and three patients who were followed up for longer than 90 days after the procedure were also excluded.
Ultimately, 40 patients who met all criteria were included in this study (Fig. 1). The study population comprised 19 men and 21 women $(52.5 \%$ ), with a mean age of 48 years (range, 20 to 76 years) and an average follow-up duration of 43 days (range, 15 to 90 days). Thirteen patients underwent steroid injection into the left hip joint and 27 into the right.

\section{Image Analysis}

We retrospectively reviewed pre-procedural MRI records analyzed by six musculoskeletal radiologists with 2 to 17 years of experience to determine if patients displayed round ligament tears or degeneration. Two musculoskeletal radiologists then came to a consensus regarding the presence of round ligament tearing or degeneration as follows. Partial tears, degeneration, and complete tears were

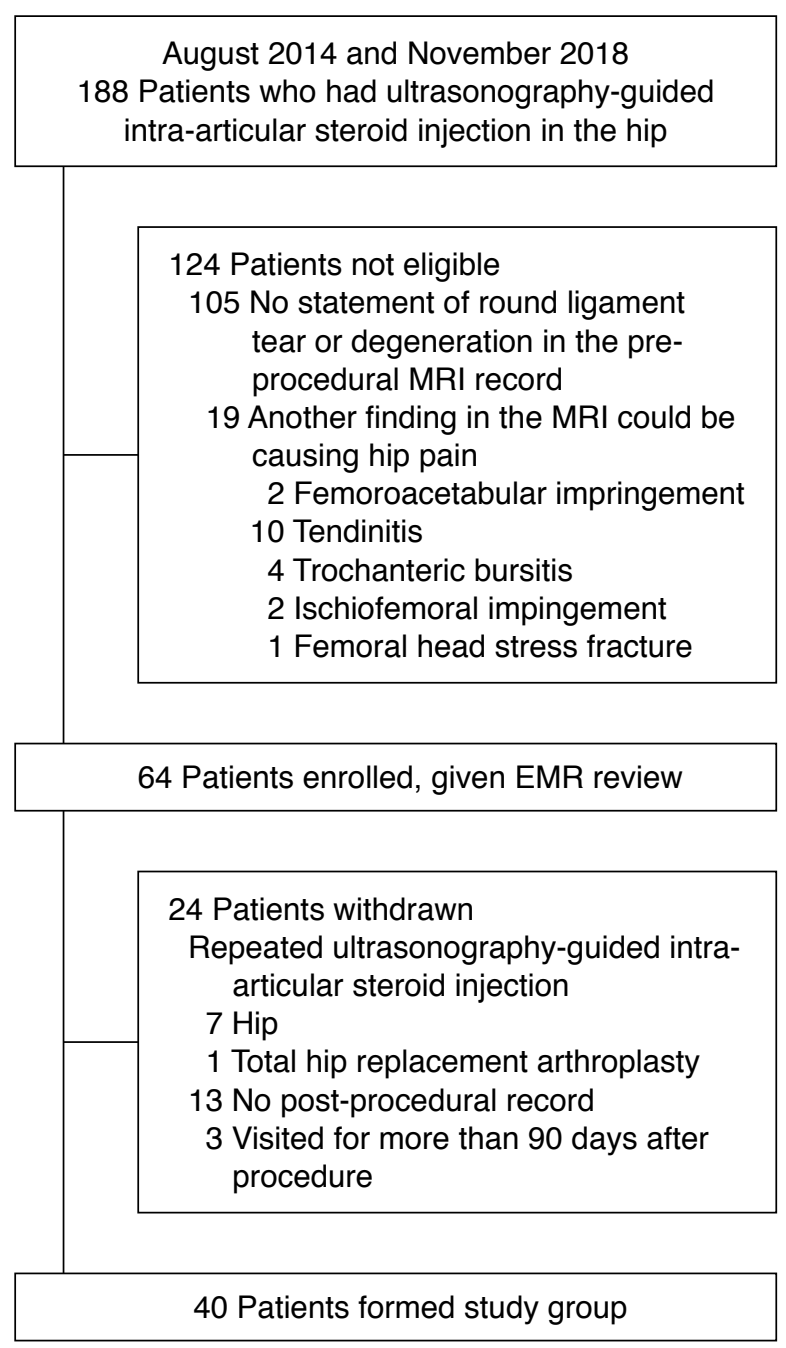

Fig. 1. Flowchart of patient selection. MRI, magnetic resonance imaging; EMR, electronic medical record. 
characterized by different MRI findings. A partial tear was defined by torn fibers or marginal irregularity accompanied by focal insufficient thickness of the ligament compared to the contralateral side [2]. Degeneration was defined by a marked increase in signal intensity on proton density-weighted fat-suppressed imaging and T2-weighted fat-suppressed imaging or swelling relative to the contralateral side [2]. A complete tear was defined by the complete absence of ligamentous material or a full-thickness disruption of the normal pathway between the fovea capitis and the transverse ligament $[2,14]$. Normal round ligaments were defined by the presence of intact fibers with normal origin and insertion, normal thickness, homogeneous hypointense signal intensity with all pulse sequences, and smooth margins. Fig. 2 shows an example MRI image from one patient each with round ligament degeneration, a partial tear, a complete tear, and normal findings. In addition, we reviewed causes of hip pain other than round ligament tear or degeneration on MRI to exclude the compounding factors of femoroacetabular impingement, calcific tendinitis, trochanteric bursitis, ischiofemoral impingement, and femoral head stress fracture [15].

\section{Injection Technique}

Each patient lay on a bed in the supine position with the hip slightly abducted and the knee pointed forward. All UISIHs were conducted by an experienced musculoskeletal radiologist (Y.C.Y.) using an iU22 ultrasound scanner (Philips, Bothell, WA, USA) equipped with a C5-1 $\mathrm{MHz}$ curved array transducer. A survey scan was first performed to determine the entry point of the needle. First, to identify the femoral head, the transducer was placed on the inguinal area parallel to the inguinal ligament. Then, the probe was rotated internally with the probe marker aimed toward the umbilicus until the femoral head, neck, and anterior capsular recess aligned in a single plane. The groin area was sterilized with a cotton ball soaked with $2 \%$ chlorhexidinealcohol and covered with a sterile cotton surgical drape centered on the planned needle entry point. The transducer was covered with a sterile ultrasound probe cover. With the probe held in an oblique longitudinal orientation so that the femoral head and neck aligned in a single plane, 2-3 $\mathrm{mL}$ of local anesthetic (lidocaine hydrochloride, 200 mg/20 mL; Daihan Pharmaceutical Co., Ltd., Seoul, Korea) was injected at the planned needle entry point to minimize the pain of spinal needle insertion. Next, the spinal needle (Quincke Bevel, 22-gauge 3-1/2 inch; TaeChang Industrial Co., Ltd., Gongju, Korea) was inserted using an in-plane approach to target the anterior capsular recess under real-time ultrasound guidance. When the needle tip was positioned inside the joint capsule, $1 \mathrm{~mL}$ of saline loaded in a 5-mL syringe was injected to confirm successful targeting of the joint space. Following this, $1 \mathrm{~mL}$ of triamcinolone acetonide (Tamceton, 40 mg/1 mL; HanAll Biopharma Co., Ltd., Seoul, Korea), 2 cc of $1 \%$ lidocaine, and $5 \mathrm{~mL}$ of normal saline (sodium chloride, 180 $\mathrm{mg} / 20 \mathrm{~mL}$; Huons Co., Ltd., Seongnam, Korea) were flushed through the extension tube. To reduce the possibility of chondrotoxicity by local anesthetics, which can be impacted by exposure time and concentration, we chose short-acting $1 \%$ lidocaine and diluted it with $5 \mathrm{~mL}$ of normal saline. The injection was considered a technical success when the hyperechoic material generated by the steroid particles was observed below the joint capsule on real-time ultrasound imaging conducted after the procedure. We also checked for the presence of immediate complications such as hematoma on the post-procedural scan (Fig. 3).

\section{Review of Clinical Data}

Short-term relief from symptoms was retrospectively evaluated at the first follow-up appointment after UISIH. One author reviewed patients' electronic medical records to assess their subjective experience of symptoms, which were classified on a 5-point scale as follows: 0 (aggravated), 1 (unchanged), 2 (symptoms improved but cannot be ignored), 3 (greatly improved; negligible symptoms), and 4 (no residual symptoms). The use of a 5 -point scale was based on an article by Lee et al. [16], and the scale was constructed in reference to the Mankoski Pain Scale (2000) [17]. A score of 0 (aggravated) was assigned if the patient described experiencing any aggravation of pain. A score of 1 (unchanged) was defined as including mentions of the pain being the same as before the procedure or unchanged from before the procedure. A score of 4 (no residual symptoms) was assigned based on mentions of a lack of problems with hip joint pain and motion. Of the patients not already classified as 0,1 , or 4, those who used positive language and whose descriptions of remaining symptoms indicated that they were mild (with word choice such as "little" or "negligible") were assigned a score of 3 (greatly improved; negligible symptoms). The remaining patients were scored as 2 (symptoms improved but cannot be ignored). If descriptions were ambiguous or a local dialect was used, two radiologists assigned a score through consensus. Patients who had a reduction of at least 2 out of 5 points were determined to have experienced symptom reduction. The same author also assessed the incidence of complications after the procedure.

\section{Statistical Analysis}

The only continuous variable analyzed in this study was follow-up duration, and it was expressed as mean \pm standard deviation. Age was categorized into three groups: 20 to 39 years, 40 to 59 years, and 60 years and older. Categorical variables were expressed as frequencies and percentages. The relationship between symptom relief and follow-up duration was analyzed using the $t$ test. The relationships between symptom relief and categorical variables such 
as age, sex, and injection side were analyzed using the chi-square test and the Fisher exact test. A P-value $<0.05$ was considered to indicate statistical significance. Statistical analysis was conducted using SAS version 9.4 (SAS Institute, Cary, NC, USA).

\section{Results}

The average follow-up periods of all 40 patients and of the patients who experienced symptom relief were 43 days (range, 15 to 90 days) and 44 days (range, 15 to 90 days), respectively. No side

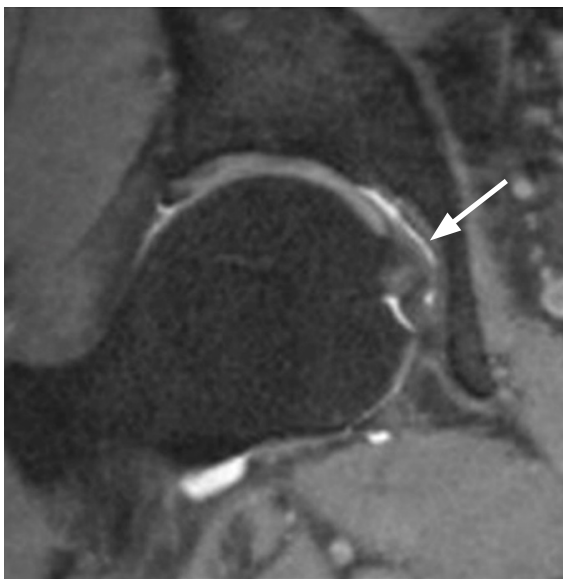

A

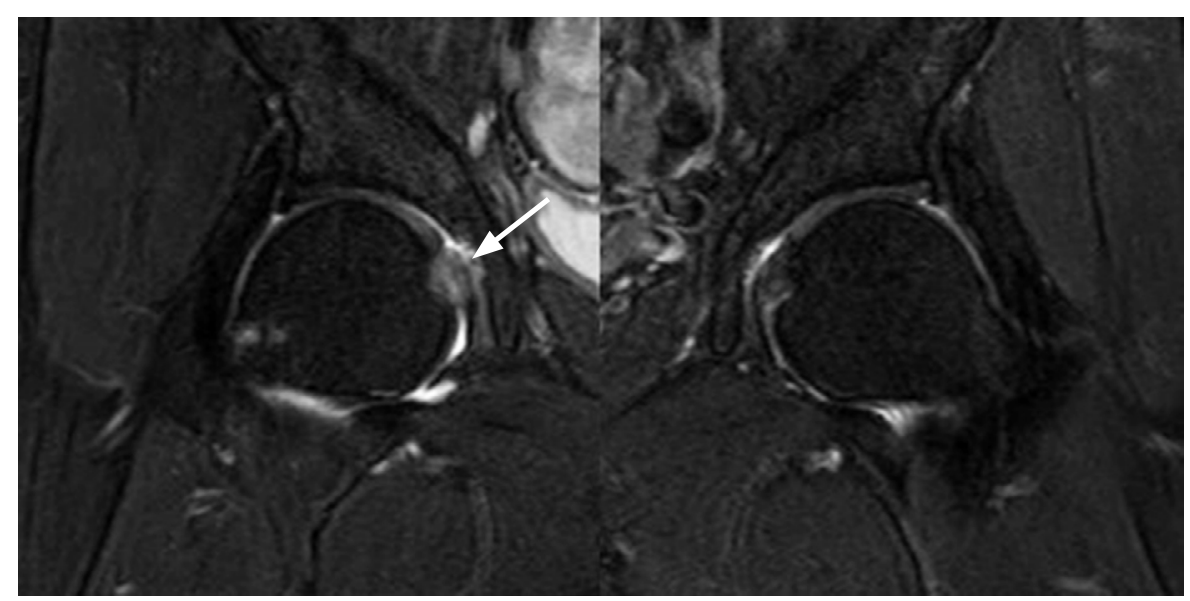

C

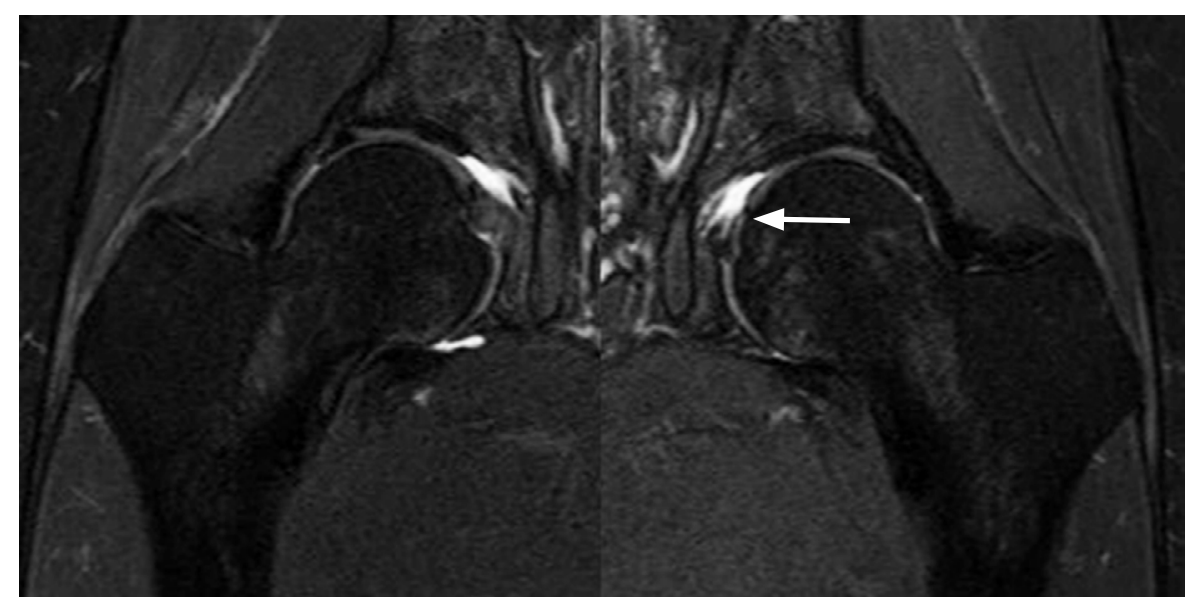

D

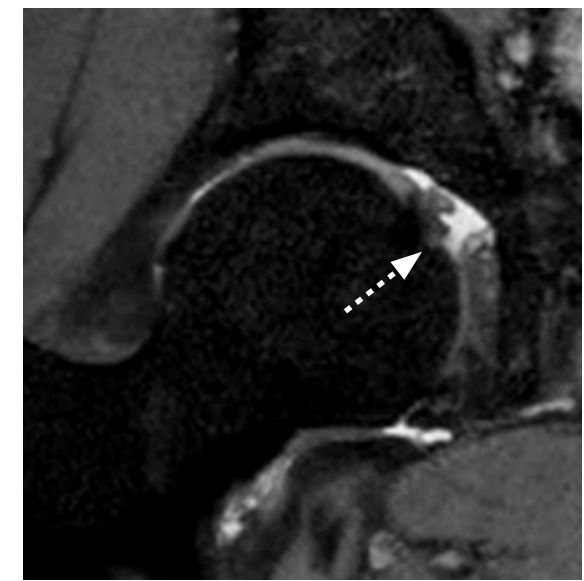

B

Fig. 2. Magnetic resonance imaging results for normal findings, complete tear, degeneration, and partial tear of the round ligament.

A. A 62-year-old man complains of buttock pain. T2-weighted fat-suppressed magnetic resonance imaging exhibits intact fibers from origin to insertion without abnormally increased signal intensity of the right round ligament (arrow). This is characteristic of a normal finding regarding the round ligament. B. A 50-year-old man complains of left hip pain. T2-weighted fat-suppressed magnetic resonance imaging exhibits fullthickness disruption of the fovea capitis (dotted arrow) adjacent to the round ligament, characteristic of a complete tear of the round ligament. C. A 46-year-old man complains of right hip pain. T2-weighted fat-suppressed magnetic resonance imaging exhibits increased signal intensity of the right round ligament (arrow), characteristic of round ligament degeneration. D. A 49-year-old woman complains of left hip pain. T2-weighted fat-suppressed magnetic resonance imaging exhibits focal insufficient thickness and marginal irregularity of the left round ligament (arrow), characteristic of a partial tear of the round ligament. 


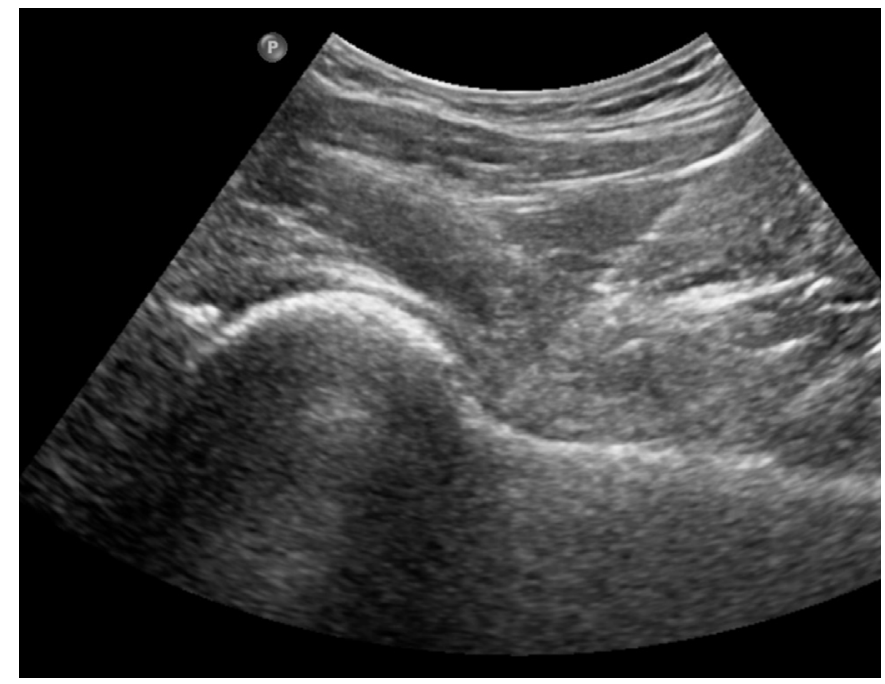

A

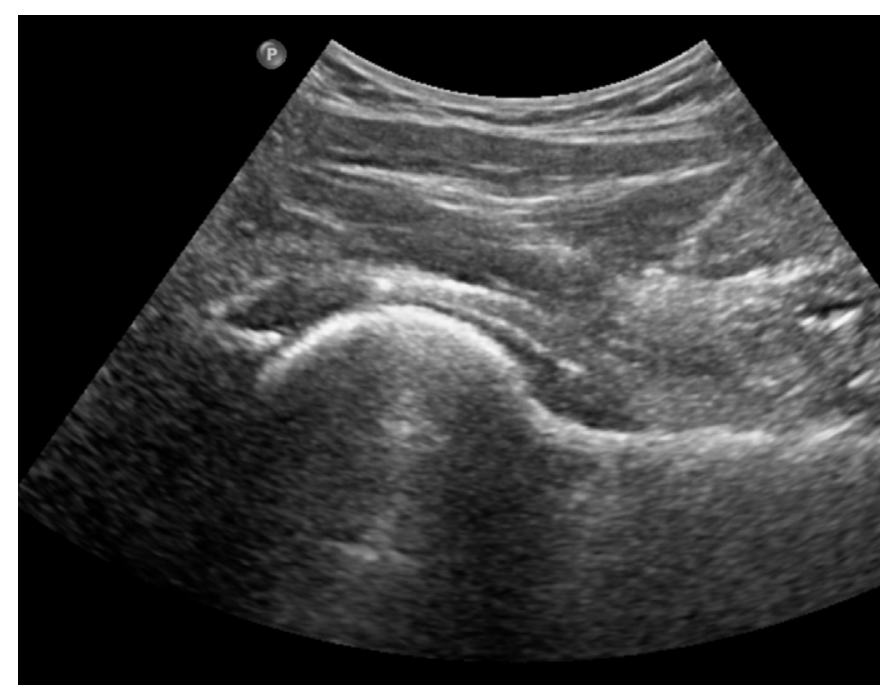

C

effects of the injections were noted. UISIH was administered on the right side in 27 patients (32.5\%) and on the left side in 13 $(67.5 \%)$. The overall technical success rate of the injections by the musculoskeletal radiologist was $100 \%$.

With respect to subjective symptom relief, five patients exhibited unchanged symptoms, 13 experienced improved symptoms, 12 experienced greatly improved symptoms, and five exhibited no residual symptoms. Unsatisfactory results were exhibited by five patients. Thus, a successful outcome was noted in 35 of the 40 patients (87.5\%). There were no significant association between symptom relief and sex, age, injection side, or follow-up duration ( $P>0.05)$, as shown in Tables 1 and 2.

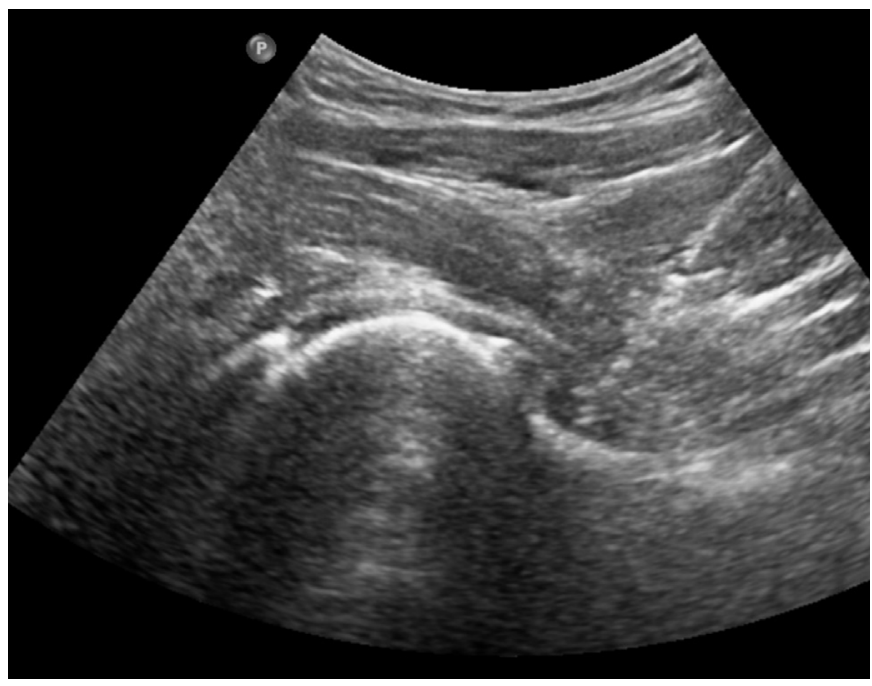

B

Fig. 3. An example of ultrasonography-guided intra-articular steroid injection in the hip.

A. A spinal needle is inserted using an in-plane approach to target the anterior capsular recess under real-time ultrasound guidance. $B$. When the needle touches the bone, a saline injection is administered to confirm successful targeting of the joint space. An injection of steroid and local anesthesia is then administered. C. A post-procedural scan is done to check for the presence of immediate complications.

\section{Discussion}

The round ligament, which has long been regarded as a vestigial structure, is a common cause of hip pain and mechanical hip symptoms [18]. The prevalence of round ligament injuries found via hip arthroscopy is $9 \%$. Such damage is classified as complete (type 1), partial (type 2), or degenerative (type 3) [19,20]. Complete round ligament tears typically occur in patients with a history of traumatic or iatrogenic joint disruption. These patients commonly exhibit other intra-articular conditions, such as chondral lesions and labral tears $[2,21-23]$. Partial round ligament tears are much more common than complete tears and primarily result from mild trauma or repeated stretching. These tears frequently occur as isolated lesions [24]. We excluded patients exhibiting complete tears of the round 
Table 1. Associations between age, sex, and injection side and symptom relief

\begin{tabular}{lccc}
\hline Parameter & Effect & No effect & P-value $^{\text {a) }}$ \\
\hline Sex & 16 & 3 & 0.654 \\
Male & 19 & 2 & \\
Female & & & \\
Age (yr) & 7 & 1 & $>0.990$ \\
$20-39$ & 23 & 3 & \\
$40-59$ & 5 & 1 & \\
$\geq 60$ & & & \\
Side & 35 & 5 & \\
All & 12 & 1 & \\
Left hip & 23 & 4 & \\
Right hip & & & \\
\hline
\end{tabular}

a)Statistical significance was assessed using the chi-square test and the Fisher exact test.

Table 2. Association between follow-up duration and symptom relief

\begin{tabular}{cccc}
\hline $\begin{array}{c}\text { Experienced } \\
\text { symptom relief }\end{array}$ & Total patients & $\begin{array}{c}\text { Duration, } \\
\text { mean } \pm \text { SD (day) }\end{array}$ & P-value $^{\text {a) }}$ \\
\hline Yes & 35 & $43.9 \pm 17.3$ & 0.461 \\
No & 5 & $37.2 \pm 27.6$ & \\
\hline
\end{tabular}

a) Statistical significance was assessed using the t test.

ligament on MRI.

Pergaminelis et al. [18], Haviv and O'Donnell [25], and Amenabar and O'Donnell [24] have reported that arthroscopic debridement of isolated round ligament tears without resection of the ligament itself potentially reduce inflammation around the torn fibers, thereby relieving pain and improving mechanical function. Intra-articular steroid injections are also used to reduce inflammation. In our study, UISIH is a treatment that is less invasive and much cheaper than arthroscopic debridement and that does not require hospitalizationachieved a successful outcome in $87.5 \%$ of patients at the first follow-up visit. No noteworthy side effects of the injections were noted. Therefore, UISIH could potentially be employed for symptom relief before a decision is made about surgery or in patients who are unsuitable for surgical treatment.

Steroids have anti-inflammatory effects, acting on nuclear steroid receptors to interfere with various inflammatory cascades. They reduce vascular permeability; inhibit the accumulation of inflammatory cells, phagocytosis, and neutrophilic superoxide production; and prevent the synthesis and secretion of several inflammatory mediators, including prostaglandins and leukotrienes [26]. Free nerve endings in the round ligament have been suggested to mediate components of the pain response. Thus, steroids may exert direct anti-inflammatory effects on inflamed nerve tissue, inhibiting the accumulation of inflammatory cells and mediators.

A study similar to the present study has been conducted previously. Byrne et al. [27] investigated the effect of intra-articular steroid-bupivacaine injections on knee pain caused by degenerative tears of the medial meniscus and demonstrated reduced pain symptoms in the majority of patients (81.7\%).

Our study had a number of limitations. First, it was a consecutive case series study, so it entailed selection bias and included no comparator group. Second, long-term data regarding symptom relief were not analyzed, so the long-term effects of UISIH could not be evaluated. Third, the measured efficacy of the treatment was based solely on subjective symptoms and not on objective measures of functional outcomes. Fourth, we did not evaluate patients' recovery from mechanical instability following the procedure. Despite its small study population and short follow-up period, we believe that this study is noteworthy, as it is the first to investigate UISIH in patients with a partial tear or degeneration of the round ligament. Given the aforementioned limitations, future prospective studies are required to further evaluate the use of UISIH in the treatment of round ligament injuries.

In conclusion, we demonstrated that UISIH was a safe and effective treatment in patients with a partial tear or degeneration of the round ligament of the femur over the course of short-term follow-up.

ORCID: Yu Sung Yoon: https://orcid.org/0000-0003-2349-5256; Young Cheol Yoon: https://orcid.org/0000-0002-7822-5344

\section{Author Contributions}

Conceptualization: Yoon YC. Data acquisition: Yoon YS, Yoon YC. Data analysis or interpretation: Yoon YS, Yoon YC. Drafting of the manuscript: Yoon YS. Critical revision of the manuscript: Yoon YS, Yoon YC. Approval of the final version of the manuscript: all authors.

\section{Conflict of Interest}

No potential conflict of interest relevant to this article was reported.

\section{Acknowledgments}

We would like to thank Editage (www.editage.co.kr) for providing English language editing.

\section{References}

1. Mayes S, Ferris AR, Smith P, Garnham A, Cook J. Atraumatic tears of the ligamentum teres are more frequent in professional ballet 
dancers than a sporting population. Skeletal Radiol 2016;45:959967.

2. Cerezal L, Kassarjian A, Canga A, Dobado MC, Montero JA, Llopis $E$, et al. Anatomy, biomechanics, imaging, and management of ligamentum teres injuries. Radiographics 2010;30:1637-1651.

3. Kraeutler MJ, Garabekyan T, Pascual-Garrido C, Mei-Dan 0. Ligamentum teres tendinopathy and tears. Muscles Ligaments Tendons J 2016;6:337-342.

4. Perumal V, Techataweewan N, Woodley SJ, Nicholson HD. Clinical anatomy of the ligament of the head of femur. Clin Anat 2019;32:90-98.

5. Amenabar T, O'Donnell J. Arthroscopic ligamentum teres reconstruction using semitendinosus tendon: surgical technique and an unusual outcome. Arthrosc Tech 2012;1:e169-e174.

6. Haversath M, Hanke J, Landgraeber S, Herten M, Zilkens C, Krauspe $R$, et al. The distribution of nociceptive innervation in the painful hip: a histological investigation. Bone Joint J 2013;95:770-776.

7. O'Donnell JM, Devitt BM, Arora M. The role of the ligamentum teres in the adult hip: redundant or relevant? A review. J Hip Preserv Surg 2018;5:15-22.

8. Philippon MJ, Pennock A, Gaskill TR. Arthroscopic reconstruction of the ligamentum teres: technique and early outcomes. J Bone Joint Surg Br 2012;94:1494-1498.

9. Botser IB, Martin DE, Stout CE, Domb BG. Tears of the ligamentum teres: prevalence in hip arthroscopy using 2 classification systems. Am J Sports Med 2011;39 Suppl:117S-125S.

10. Dehao BW, Bing TK, Young JL. Understanding the ligamentum teres of the hip: a histological study. Acta Ortop Bras 2015;23:29-33.

11. Micu MC, Bogdan GD, Fodor D. Steroid injection for hip osteoarthritis: efficacy under ultrasound guidance. Rheumatology (Oxford) 2010;49:1490-1494.

12. Martin HD, Palmer IJ. History and physical examination of the hip: the basics. Curr Rev Musculoskelet Med 2013;6:219-225.

13. Kivlan BR, Martin RL, Sekiya JK. Response to diagnostic injection in patients with femoroacetabular impingement, labral tears, chondral lesions, and extra-articular pathology. Arthroscopy 2011;27:619627.

14. Datir A, Xing M, Kang J, Harkey P, Kakarala A, Carpenter WA, et al. Diagnostic utility of MRI and MR arthrography for detection of ligamentum teres tears: a retrospective analysis of 187 patients with hip pain. AJR Am J Roentgenol 2014;203:418-423.
15. Fischer W, Guermazi A, Roemer F, Carrino JA, Grainger AJ, Kijowski R, et al. MRI-Essentials.com. Augsburg: MRI-Publisher, 2017;419-474.

16. Lee JW, Kim SH, Choi JY, Yeom JS, Kim KJ, Chung SK, et al. Transforaminal epidural steroid injection for lumbosacral radiculopathy: preganglionic versus conventional approach. Korean J Radiol 2006;7:139-144.

17. Mankoski A. Mankoski pain scale [Internet]. Andrea Mankoski, 2000 [cited 2019 Dec 10]. Available from: http://www.valis.com/ andi/painscale.html.

18. Pergaminelis N, Renouf J, Fary C, Tirosh O, Tran P. Outcomes of arthroscopic debridement of isolated ligamentum teres tears using the iHOT-33. BMC Musculoskelet Disord 2017;18:554.

19. de SD, Phillips M, Philippon MJ, Letkemann S, Simunovic N, Ayeni OR. Ligamentum teres injuries of the hip: a systematic review examining surgical indications, treatment options, and outcomes. Arthroscopy 2014;30:1634-1641.

20. Gray AJ, Villar RN. The ligamentum teres of the hip: an arthroscopic classification of its pathology. Arthroscopy 1997;13:575-578.

21. Byrd JW, Jones KS. Traumatic rupture of the ligamentum teres as a source of hip pain. Arthroscopy 2004;20:385-391.

22. Philippon MJ, Kuppersmith DA, Wolff AB, Briggs KK. Arthroscopic findings following traumatic hip dislocation in 14 professional athletes. Arthroscopy 2009;25:169-174.

23. Guanche CA, Sikka RS. Acetabular labral tears with underlying chondromalacia: a possible association with high-level running. Arthroscopy 2005;21:580-585.

24. Amenabar T, O'Donnell J. Successful treatment of isolated, partial thickness ligamentum teres (LT) tears with debridement and capsulorrhaphy. Hip Int 2013;23:576-582.

25. Haviv B, O'Donnell J. Arthroscopic debridement of the isolated ligamentum teres rupture. Knee Surg Sports Traumatol Arthrosc 2011;19:1510-1513.

26. Ayhan E, Kesmezacar H, Akgun I. Intraarticular injections (corticosteroid, hyaluronic acid, platelet rich plasma) for the knee osteoarthritis. World J Orthop 2014;5:351-361.

27. Byrne C, Alkhayat A, Bowden D, Murray A, Kavanagh EC, Eustace SJ. Degenerative tears of the posterior horn of the medial meniscus: correlation between MRI findings and outcome following intraarticular steroid/bupivacaine injection of the knee. Clin Radiol 2019;74:488.e1-488.e8. 